\title{
Processo de (des)territorialidade em uma comunidade rural na Bahia
}

\author{
Process of (des)territoriality in a rural community in Bahia
}

\section{Proceso de (des)territorialidad en una comunidad rural en Bahia}

\author{
Divaney Mamédio ${ }^{1}$ \\ Jesus Manuel Delgado Mendez ${ }^{1}$ \\ Renato de Almeida ${ }^{1}$ \\ Simone Barequeiro de Santana ${ }^{1}$
}

Recebido em 14/01/2019; revisado e aprovado em 31/10/2019; aceito em 19/11/2019

DOI: http://dx.doi.org/10.20435/inter.v22i1.2347

\begin{abstract}
Resumo: A globalização do meio rural ocorre paralelamente ao processo de desterritorialização, gradativo, intenso e generalizado, despertando reflexões sobre os temas identidade e território. Este estudo visa descrever como uma empresa fumageira influenciou na perda de identidade sociocultural da Comunidade Rural de Laranjeiras, Muritiba (BA), mediante processos de desterritorialização. Os dados foram coletados e descritos a partir da observação aberta, com uso de entrevista não estruturada, marcada por conversas informais. A presença da empresa desencadeou intenso processo de "des-pertencimento"/desenraizamento familiar, provocando perda de identidade sociocultural e costumes, além da consequente redução de espaço físico da comunidade. Foi destacada a crescente insalubridade local pelo aumento de materiais particulados, intenso tráfego de veículos e o odor característico de insumos químicos na monocultura do fumo. Ainda assim, a comunidade parece acreditar que a indústria é "um mal necessário", pois oferece emprego à maioria da comunidade. Verificou-se, também, o êxodo dos jovens, que se deslocaram em busca de melhores salários e enfrentaram o processo de desenraizamento. Outra problemática vivenciada pela comunidade é o aparecimento de doenças atribuídas ao uso indiscriminado de agrotóxicos na lavoura do fumo, por ação da empresa. É possível concluir que a comunidade em questão vivencia desenraizamento e desterritorialização sociocultural e econômica, associados à expropriação de direitos e costumes tradicionais, inseridos no processo de globalização do meio rural.
\end{abstract}

Palavras-chave: desenraizamento; identidade; território.

Abstract: The globalization process of rural areas occurs in parallel with gradating, intense, and generalized lack of territoriality process, bringing out philosophical reflections over topics as identity and territory. The main objective of this study is to determine how a tobacco enterprise could influence the social and cultural identity of the rural community of Laranjeiras, Muritiba (BA), throughout some processes of "dis-belonging"/ uprooting. Data was collect and described using an open observation method, through structured interviews and informal conversations. We noted that the company presence had provoked an intense process of breaking family roots, with loss of identity on social and cultural traditions, in addition to the consequent reduction in the physical space of community. It should be noted the rise in insalubrity by the increase of particle pollution, heavy traffic of large trucks, and the characteristic odor of chemical inputs in tobacco monoculture. Still, the community seems to believe that industry is "a necessary evil" given the supply of jobs. It was also verified the exodus of the young for better opportunities and that they had faced the uprooting. Another problem in the community is the appearance of diseases attributed to the uses of agrochemicals commonly applied on tobacco cultivation, by the company. It is possible to conclude that the community is still suffering a process of lack of territory's social and cultural identity, associated with the common consequences of rural environment globalization, as the loss of land and traditional rights and customs.

Keywords: uprooting; identity; territory.

Resumen: La globalización del medio rural ocurre paralelamente a un proceso de desterritorialización, gradual, intenso y generalizado, despertando reflexiones sobre temas como identidad y territorio. Este estudio pretende describir cómo una empresa tabacalera influenció en la pérdida de identidad social y cultural de la comunidad rural de Laranjeiras, Muritiba (BA), mediante procesos de "des-pertenencia"/ desarraigo. Los datos se recopilaron y describieron mediante método de observación abierta, con uso de entrevistas no estructuradas, marcadas por conversaciones informales. Se observó que la presencia de la empresa había provocado un intenso proceso de ruptura en las raíces familiares, con la pérdida de la identidad y las tradiciones sociales y culturales, además de la consiguiente reducción en el espacio físico de

\footnotetext{
${ }^{1}$ Universidade Federal do Recôncavo da Bahia, Cruz das Almas, Bahia, Brasil.
} 
la comunidad. La creciente insalubridad se destacó por el aumento de la contaminación por partículas, el tráfico pesado de camiones y el olor característico de los insumos químicos en el monocultivo de tabaco. Sin embargo, la comunidad parece creer que la industria es "un mal necesario" dada la oferta de empleos. También se verificó el éxodo de los jóvenes por mejores oportunidades de trabajo y su enfrentamiento a lo desarraigo. Otra problemática vivenciada por la comunidad fue la aparición de enfermedades atribuidas al uso indiscriminado de pesticidas comúnmente aplicados en el cultivo de tabaco, por parte de la empresa. Es posible concluir que la comunidad todavía sufre un proceso de falta de identidad social y cultural del territorio, asociado con las consecuencias comunes de la globalización del medio rural, como la pérdida de tierras, los derechos y costumbres tradicionales.

Palabras claves: desarraigo; identidad; territorio.

\section{INTRODUÇÃO}

Este artigo analisará as mudanças ocorridas na vida dos moradores da comunidade rural de Laranjeiras, a partir da instalação de uma empresa fumageira no território desta comunidade, enfatizando, principalmente, a perda ao direito da exploração da terra pelos comunitários, iniciada por meio de um processo gradual de aquisição de novas terras do entorno da comunidade por parte da empresa, incluindo alguns cursos d'águas, que tradicionalmente abasteciam a comunidade, bem como áreas de lazer.

A comunidade de Laranjeiras se caracteriza pela predominância de agricultores familiares de classe média baixa, em sua maioria, sendo um quarto destes considerados analfabetos e com baixos indicadores socioeconômicos, tal como descrito nos estudos desenvolvidos nessa mesma comunidade (SANTOS et al., 2015). A posse da terra pelas famílias da região se deu por meio de heranças advindas dos antecessores familiares, ou seja, encontra-se na família há várias gerações. A chegada de um capital estrangeiro (empresa fumageira multinacional) ocasionou conflitos de interesse por ocupação dos espaços físicos da comunidade, o que fez com que muitas famílias cedessem às pressões exercidas pela empresa para que vendessem suas terras, passando de donos a empregados da empresa.

A dinâmica que vem ocorrendo na comunidade rural, foco deste estudo, não difere de várias outras localidades que têm sofrido com a invasão e perda de seus espaços físicos e identidade cultural. É por esta razão que Santos e Silva (2016) chamam atenção para a existência no espaço rural brasileiro de cenários diversificados e conflitantes, além de atores sociais de múltiplas vivências, e tudo isso faz contrastar as diferentes escalas de agronegócio, desde a produção familiar até a grande escala de produção.

Nessa perspectiva, busca-se aqui discutir a temática abordada não apenas com enfoque nas relações de demarcação de terras, mas voltando a atenção para as questões relacionais entre as partes envolvidas e, principalmente, o círculo vicioso de construção, desconstrução e reconstrução das identidades dos sujeitos e o sentimento de pertencimento, de maneira a olhar o "lugar" não somente como berço provedor de renda econômica, mas também de forma simbólica, como espaço de construção das relações socioculturais.

O presente trabalho inicia sua fundamentação teórica ao apresentar os conceitos de enraizamento, territorialidade e o processo de desterritorialização. Na metodologia, foi apresentada a descrição da área e os procedimentos de coleta e análise de dados obtidos em conversas informais com quase 100 moradores. A inserção prévia na vida cotidiana da comunidade permitiu a construção de uma confiança mútua, traduzida na descrição da trajetória dos atores sociais, permeada por conflitos de ideias identificadas na fala da maioria dos moradores de 
Laranjeiras ao comentarem os reais impactos ocasionados pela presença da indústria fumageira naquele meio rural. Por fim, com base nos vários momentos reflexivos com a comunidade, sejam nas conversas em quintais das casas, sejam na igreja comunitária, escola ou vias de acesso à comunidade, o presente estudo se propôs a identificar e discutir as implicações originadas dessa "relação". Os registros sobre as mudanças no modo de vida da comunidade e as queixas quanto ao uso de agrotóxicos por parte da empresa fumageira foram articulados com os conceitos inicialmente apresentados.

Em suma, trata-se de um estudo de caso, em que desejamos saber até que ponto a presença da indústria fumageira influenciou na perda de identidade sociocultural da Comunidade Rural de Laranjeiras, Muritiba, BA, mediante o processo de desterritorialização.

\section{FUNDAMENTAÇÃO TEÓRICA}

A Comunidade Rural de Laranjeiras vivencia um nítido processo de perda de identidade sociocultural, induzida pela acelerada redução de espaço territorial. Daí a importância de uma reflexão do conceito de territorialidade. Afinal, as mudanças econômicas, políticas e culturais que a sociedade contemporânea enfrenta, associadas aos avanços tecnológicos e suas implicações, impulsionam a busca por novas ferramentas teóricas, metodológicas e conceituais, que permitam maior compreensão do mundo. Todavia, isso depende da transposição de barreiras das diversas áreas do saber organizadas em torno de problemáticas, que, uma vez analisadas, permitem responder a novas necessidades interdisciplinares.

Além disso, diversos pesquisadores têm dado atenção especial às consequências ocasionadas pelos avanços da tecnologia e da globalização, sobretudo quanto ao processo de desenraizamento ou desterritorialização, que ganha força dia a dia e torna-se, gradativamente, intenso e generalizado (IANNI, 1993). Esse processo de desterritorialização se configura pela possível ruptura do sentimento de pertencimento de um indivíduo ao seu território (OLIVEIRA, 2011). Oliveira (2011) enfatiza ainda que o fato de se sentir confortável no território com o qual se identifica e de estreitar os laços interpessoais com os agentes que nele habitam é um aspecto da natureza do próprio ser humano, ao qual se estabelece a construção de sua identidade, e é por isso que a ligação do homem ao território é de grande relevância.

Constata-se nas ciências sociais, por exemplo, grande discussão acerca da dimensão espacial referente aos fenômenos sociais e econômicos (SCHNEIDER; TARTARUGA, 2004). Tal interesse encontra-se motivado pelas tentativas de explicar, com base em suas configurações espaciais, os indutores de desenvolvimento socioeconômico de áreas rurais em detrimento de outras regiões. De fato, a variável espacial tem sido apontada como de fundamental relevância para compreender o dinamismo regional e a ligação com as ações praticadas por seus atores e instituições.

Essa temática demonstra maior significância se considerarmos sua multiplicidade de sentidos, mas também o fato de que as ações sociais contemporâneas fortemente a destacam no contexto referencial espaço/tempo. Além do mais, observa-se divergência epistemológica conceitual dos termos supracitados: identidade e território.

Duarte e Luzio (2008) afirmam que, dependendo da conformação socioespacial, o território pode admitir múltiplos significados, além de particularidades resultantes das distintas dimensões envolvidas em sua constituição e manutenção. A dimensão simbólica, por exemplo, encontra-se 
repleta de significados afetivos, vinculados à construção da história individual e coletiva. Portanto, é considerada de base identitária, pois dela são gerados sentimentos de pertencimento e enraizamento.

Existem múltiplas definições para o território (SANTOS; SILVA, 2016), sendo que este pode ser interpretado por meio das relações de poder nele estabelecidas, a partir de construções sóciohistóricas, e estar relacionado tanto ao patrimônio físico quanto aos valores impressos numa sociedade (TEIXEIRA; MELO; FRANÇA, 2011; SILVA, 2012). Para o Ministério do Desenvolvimento Agrário (BRASIL, 2005, p. 7), a definição de território é:

[...] um espaço físico, geograficamente definido, geralmente contínuo, compreendendo cidades e campos, caracterizado por critérios multidimensionais, tais como o ambiente, a economia, a sociedade, a cultura, a política e as instituições, e uma população com grupos sociais relativamente distintos, que se relacionam interna e externamente por meio de processos específicos, onde se pode distinguir um ou mais elementos que indicam identidade e coesão social, cultural e territorial.

Para Abramovay (2006) e Freitas (2016), o território é constituído por interações interpessoais, responsáveis pela construção das relações sócio-históricas e da identidade individual e coletiva dos agentes, assim como pelas intervenções praticadas por estes.

Haesbaert (2004a) e Freitas (2016) chamaram atenção para que o território seja também considerado como um espaço de representação simbólica, e que este não se desvencilha do entendimento do que seja a concepção de territorialidade. Sucintamente, a territorialidade é concebida como um comportamento humano espacial, a partir do processo de delimitação, valorização e controle do espaço geográfico, em que vigoram formas de comunicação baseadas na construção social (MORAES; COSTA, 1984; SACK, 1986). Do ponto de vista de Haesbaert (2007), a territorialidade não é apenas uma abstração analítica,

[...] é também uma dimensão imaterial, no sentido ontológico de que, enquanto imagem ou símbolo de um território, existe e pode inserir-se eficazmente como uma estratégia políticocultural, mesmo que o território ao qual se refira não esteja concretamente manifestado. (p. 25).

De acordo com Albagli (2004), no momento em que se incorpora o conceito de territorialidade às ciências humanas e sociais, passamos a avaliar a condição humana a partir da dimensão espacial, tornando-a mais rica e complexa, referindo-se então:

[...] às relações entre um indivíduo ou grupo social e seu meio de referência, manifestando-se nas várias escalas geográficas - uma localidade, uma região ou um país - e expressando um sentimento de pertencimento e um modo de agir no âmbito de um dado espaço geográfico. No nível individual, territorialidade refere-se ao espaço pessoal imediato, que em muitos contextos culturais é considerado um espaço inviolável. Em nível coletivo, a territorialidade torna-se também um meio de regular as interações sociais e reforçar a identidade de grupo ou comunidade. (ALBAGLI, 2004, p. 28).

Duarte e Luzio (2008) analisaram também o conceito de enraizamento e a concepção de sua construção e desconstrução na vida do homem, bem como a correlação entre território e territorialidade. Weil (2001) diz que a identidade do individuo será enraizada conforme o contexto no qual está inserido, afirmando ainda que o enraizamento talvez represente a necessidade mais importante e desconhecida da alma humana, pois existe uma condição geradora de sofrimento, denominada "doença do desenraizamento", ocasionada pela dominação econômica (dinheiro) que promove a ruptura de outros vínculos sociais: 
A conquista colonial causa desenraizamento e morte com a supressão brutal das tradições. A conquista militar, também. Mas a dominação econômica de uma região sobre outra, no interior de um país, causa a mesma doença. Age como conquista colonial e militar ao mesmo tempo, destruindo raízes, tornando os nativos estrangeiros em sua própria terra. (BOSI, 1999, p. 17).

Bosi (1999) relata que a cultura é também atingida pelo desenraizamento, fragmentando-se. Isso remete a certo tipo de escravidão, isolamento e sofrimento. A autora observa que o avanço do modelo produtivista capitalista transforma tudo e todos em mercadorias, expropriando os saberes daqueles que não acompanham a rotatividade da economia global. Este modelo desarticula e destrói valores praticados pela coletividade, resultando no esvaziamento de significação do trabalho humano.

Em seus estudos, lanne (1993) se referiu ao avanço da globalização como elemento responsável por acelerar os processos de desterritorialidade e desenraizamento, interferindo não somente no plano individual e coletivo, mas, simultaneamente, nas diversas esferas, desestabilizando pessoas e pensamentos, rompendo tradições e levando ao esvaziamento de sentidos e significados.

Nesse sentido, para Pagès, Bonetti e Gaulejac (1987, p. 119-21), a desterritorialização é:

[...] conjunto dos mecanismos que consistem em separar o indivíduo de suas origens sociais e culturais, em destituí-lo de sua história pessoal para reescrevê-la no código da organização, em desenraizá-lo de sua terra originária para melhor enraizá-lo [...] apagar suas referências originais para substituí-las por outras, conforme os interesses da empresa. [...] Trata-se, portanto, realmente de "deformar" o indivíduo em relação aos seus laços culturais e geográficos para criar uma personalidade nova que está impregnada do espírito e das normas da empresa.

Em estudos sobre as contradições da modernidade no processo de des/re/territorialização do lugar, Bortone, Ludwig e Xavier (2016) enfatizaram que o ato de territorializar desencadeia o processo de desterritorialização, e desse culmina a reterritorialização, isto é, a perda da identidade sociocultural e o desenraizamento de uma comunidade, para que ocorra a construção de novos territórios e, com ela, o estabelecimento de uma nova identidade do lugar.

Percebe-se que o processo de decadência de uma comunidade rural não se dá somente quando esta se encontra mais marginalizada da sociedade, com a negação dos seus direitos básicos para sobrevivência, mas também a partir do processo gradativo da desvalorização de seu espaço físico, de suas tradições, do seu modo de vida e da capacidade de socialização.

\section{METODOLOGIA}

\subsection{Caracterização da área de estudo}

O munícipio de Muritiba (BA) está inserido na região do Recôncavo da Bahia (12³8'13"S e $39^{\circ} 5^{\prime} 45^{\prime \prime} \mathrm{W}$ ) e tem 29.387 habitantes, sendo que sua população em idade ativa se ocupa da agricultura, pecuária e silvicultura (INSTITUTO BRASILEIRO DE GEOGRAFIA E ESTATÍSTICA [IBGE], 2017). Este estudo foi desenvolvido na Comunidade Rural de Laranjeiras, a qual é formada por aproximadamente 110 famílias de agricultores familiares produtores, cada uma composta por quatro ou mais residentes. A principal característica da comunidade é a presença de extensão de terra ocupada pela monocultura do fumo, mantida por empresa de capital estrangeiro. 


\subsection{Sujeitos da pesquisa}

O foco da pesquisa foi centralizado nos moradores da Comunidade Rural em questão. A identidade dos sujeitos participantes da pesquisa foi mantida em sigilo, identificados com a letra "M" (Morador), seguida de letras sequenciais, à medida que ocorreram as entrevistas. O perfil socioeconômico desta população foi descrito em estudo prévio realizado por Santos et al. (2015). As análises dos impactos da empresa fumageira sobre a vida comunitária foram realizadas com jovens e adultos desta comunidade.

\subsection{Coleta e análise dos dados}

Para avaliar a opinião dos moradores diante da presença da empresa fumageira nos arredores da Comunidade, foi realizado levantamento descritivo, com observação aberta; ou seja, quando o observador é visível aos observados, que sabem ser objeto de pesquisa (VIANNA, 2007).

Fez-se uso de entrevista não estruturada, marcada por conversas informais direcionadas por perguntas abertas ou de sentido genérico, de modo a avaliar o censo crítico dos entrevistados em relação à empresa fumageira.

A coleta de dados, realizada com cerca de 100 moradores da Comunidade, ocorreu entre agosto e outubro de 2013. Foram conduzidos registros fotográficos de interesse da pesquisa. As anotações tiveram registros cursivos (contínuo), posteriormente transcritos (DANNA; MATOS, 2006).

\section{RESULTADOS E DISCUSSÃO}

O conceito de territorialidade foi definido em 1920 pelo ornitólogo inglês H. E. Howard como "a conduta característica adotada por um organismo para tomar posse de um território e defendê-lo contra os membros de sua própria espécie". Conceito este que pode ser seguramente empregado ao contexto da Comunidade Rural de Laranjeiras, pois este grupo social entende o território como algo gerador de sustento financeiro e base de suas raízes e da identidade. Falar de território é se referir primeiramente à apropriação social do espaço e, posteriormente, ao entendimento de que este guarda uma dimensão material e uma dimensão simbólica. Logo, o território compreende conjunto de variáveis incorporadas por uma população; em suma, um lugar cuja história apresenta todas as manifestações características das tradições familiares rurais.

Dada a complexidade da sociabilidade humana, abrangendo as diversas escalas geográficas e sociais, a territorialidade dos grupos humanos pode ser estruturada, segundo Soja (1971), por três básicos ingredientes: os sentidos de identidade espacial; de exclusividade; e uma compartimentação da interação humana no espaço. A identidade espacial se manifesta como um sentimento de afetividade ou de topofilia ${ }^{2}$, conforme Yi-fu Tuan (1980; 1983). O senso de exclusividade, frequentemente latente, apenas surge quando existe ameaça de invasão ao espaço familiar por parte de estranhos à cultura e ao próprio ambiente, o que favorece uma atitude de autossegregação coletiva. A interação espacial estabelece-se num jogo de vantagens mútuas em função da proximidade.

Este conceito torna perceptível, na conversa com moradores da Comunidade, as três camadas estruturais propostas por Soja (1971), pois foram constatados elos sentimentais que

\footnotetext{
${ }^{2}$ Topo: lugar; Filia: sentimento positivo. Topofilia é descrito como sendo "o elo afetivo entre a pessoa e o lugar ou ambiente físico". Uma pessoa pode ter uma relação com lugares de maneira topofílica ou topofóbica.
} 
os ligam aos seus "pedaços de chão", já que as propriedades são heranças familiares. Assim, evidencia-se a relação dos sujeitos envolvidos com a exploração da terra para a subsistência (alimentação) e os chamados excedentes da produção, destinados à comercialização nos centros urbanos, prática típica da Agricultura Familiar.

Foram destacadas também as memórias afetivas do local onde a maioria nasceu e/ou viveu os processos de descobertas e aprendizados, além da construção da teia familiar. Evidenciou-se o sentimento de frustração e/ou indignação por aqueles que se viram obrigados a se desfazerem de suas propriedades, por causa das investidas da empresa fumageira que ofereceu tentadoras propostas de compras de terreno para expandir sua propriedade, causando a redução territorial da comunidade e da cultura local. Aqui se apresenta a terceira vertente básica (a econômica), relacionada à discussão sobre a conceituação de território, que serve como fonte de recurso (dimensão espacial das relações econômicas) (HAESBAERT, 2004b).

Alguns moradores se viram obrigados a abandonar suas casas por causa das condições insalubres que se estabeleceram no local: a constante presença de partículas de poeira suspensas no ar, intenso tráfego de carros de grande porte da empresa e o odor característico do uso intenso de insumos químicos na monocultura do fumo.

A entrada de uma empresa de grande porte e capital financeiro na Comunidade Rural trouxe nova estética ao local, mudando o contexto da região e estabelecendo um território diferente dentro da territorialidade pré-existente, ou seja, um lugar dentro de outro lugar. Além das modificações na paisagem e as mudanças no modo de vida dos moradores, observou-se que grande parte dos agricultores familiares deixou este ramo para se tornar trabalhador assalariado, mudando radicalmente o seu relacionamento com o território, a família e a comunidade como um todo.

É neste novo cenário de mudanças que se inicia o processo de "des-pertencimento" ou desenraizamento da terra, acompanhado pela perda de espaço físico, já que o território das famílias foi delimitado (reduzido) pelas demarcações da empresa. Assim, muitos moradores se viram sem possibilidade de crescimento e ampliação de horizontes, obrigados a procurar complementação de sua renda na empresa, para manter a sustentabilidade de suas famílias.

É imperativo destacar, portanto, o flagrante processo de desterritorialização ${ }^{3}$, em que parte da cultura e dos costumes de uma comunidade foi abandonada para dar lugar a outro modo de vida. Santos (1999) defende que as coisas estão em constante movimento em nossa sociedade e que as pessoas mudam de lugar frequentemente, assim como mudam também de ideia a todo tempo, e que é desta rotatividade que surge o conceito de desterritorialização ou, segundo o autor, a desculturização.

No entanto, Haesbaert (2004a, p. 32) afirma que, ao mesmo tempo que ocorre desterritorialização, dão-se também as territorializações e reterritorializações, referindo-se à nova concepção de "multiterritorialidade "4"; um concomitante processo de destruição e construção de territórios, combinados nas mais variadas esferas e formas organizativas. O autor ratifica a multiterritorialidade ao ressaltar que esta "alternativa conceitual", segundo suas palavras, não

\footnotetext{
3 "Desterritorialização" é um termo para o deslocamento de identidades, pessoas e significados que é endêmico ao sistema do mundo pós-moderno (KAPLAN, 1990, p. 358).

${ }^{4}$ [...] a existência do que estamos denominando multiterritorialidade, pelo menos no sentido de experimentar vários territórios ao mesmo tempo e de, a partir daí, formular uma territorialização efetivamente múltipla, não é exatamente uma novidade, pelo simples fato de que, se o processo de territorialização parte do nível individual ou de pequenos grupos, toda relação social implica uma interação territorial, um entrecruzamento de diferentes territórios. Em certo sentido, teríamos vivido sempre uma "multiterritorialidade" (HAESBAERT, 2011, p. 344).
} 
nega a existência da desterritorialização, mas se trata de um processo indissociável ligado à sua contraface, os movimentos de (re)territorialização.

Foram inúmeras as manifestações de insatisfação da maioria dos moradores. Porém, parecem acostumados/acomodados à condição de assalariados que a empresa Ihes oferece, com maior estabilidade diante do trabalho anterior em suas propriedades, mesmo admitindo o interesse empresarial. Exemplifica-se, assim, a interação espacial citada por Soja (1971, p. 34). Tal indignação perante a relação empresa-comunidade é visível na fala de um morador (M.a): "As pessoas não querem dizer nada porque têm medo de perder o emprego; a indústria fumageira é o sustento de muita gente aqui".

Portanto, estabeleceu-se severa divisão do trabalho local, nunca antes existente. Moradores deixaram de ser donos de seu lugar para compor a massa produtiva da empresa (empregados), submetendo-se aos mandos e desmandos de quem veio de fora moldando, a todo custo, os costumes e ritmos da comunidade. Isso ocasionou fragilização da estrutura organizacional da comunidade, contribuindo para a perda de identidade social e cultural.

É neste aspecto que Bosi (1999) retrata o cenário da perda de autonomia, da subordinação ao capital empresarial, da estrangulação das tradições comunitárias e, por conseguinte, da organicidade de tais núcleos, como processo que desenraiza o ser humano e o torna escravo do capital. Então, parece também apropriado descrever o atual nível de participação comunitária em Laranjeiras.

O comportamento e os relatos dos moradores de Laranjeiras apontaram que as decisões e/ou ordens sempre partiram da administração da empresa fumageira, sem debate algum com a Comunidade, ainda que as decisões trouxessem impactos positivos ou negativos. E, assim, a empresa fumageira foi ganhando, cada vez mais, o espaço físico na comunidade. Além do mais, constatou-se que as organizações existentes na comunidade, a exemplo das associações, foram criadas com o intuito de conseguir recursos, equipamentos, cursos de formação e outros benefícios de interesse das associações junto à administração municipal.

Ressaltam-se, ainda, experiências pretéritas que foram desenvolvidas nessa mesma comunidade, com a oferta gratuita de cursinho pré-vestibular aos moradores, de modo que esses tivessem condições mais igualitárias de concorrer a vagas nas universidades públicas. No entanto, naquele momento, Muritiba vivenciava a campanha eleitoral. O gestor, que pleiteava a reeleição, ludibriou a comunidade fornecendo-Ihe transporte até as escolas localizadas na sede do município. Desde então, os moradores de Laranjeiras abandonaram o projeto do grupo PET. Porém o serviço de transporte escolar foi suspenso pelo gestor após um mês de funcionamento, provocando ruptura nas oportunidades de estudo da comunidade.

Pimbert e Pretty (2000, p. 196-8) descreveram sete tipologias para tentar oferecer uma qualificação mais apropriada do termo "participação". O presente estudo nos leva a ponderar as seguintes tipologias: 1) Participação Passiva, em que a informação é unilateral e dividida apenas entre agentes externos (empresa fumageira), de modo que as reações das pessoas (Comunidade) não são consideradas e essas apenas tomam conhecimento no momento das implementações das decisões. 2) Participação por Incentivos Materiais, em que a Comunidade oferta sua força de trabalho em troca de bens de consumo e/ou materiais; embora perca o interesse e abandone a atividade desempenhada à medida que se esgotam os incentivos. Assim, concordamos com Rahnema (1992, p. 121), que qualificou essas duas tipologias como aquelas que apresentam resultados superficiais, de baixo impacto e pouco duradouras na vida das pessoas, de modo que jamais as levarão ao campo da ação. 
Mais uma vez, torna-se perceptível e notória a negação aos costumes, tradições comunitárias e formas organizativas, de tal modo que o "desenvolvimento" não se deu na perspectiva apresentada por Haesbaert, quando afirma que:

Enquanto continuum dentro de um processo de dominação e/ou apropriação, o território e a territorialização devem ser trabalhados na multiplicidade de suas manifestações, que é também e, sobretudo, multiplicidade de poderes, neles incorporados através dos múltiplos sujeitos envolvidos (tanto no sentido de quem sujeita quanto de quem é sujeitado, [...]). (HAESBAERT, 2007, p. 22).

Antes da implantação da empresa na região, a comunidade vivia da produção de laranjas, daí o nome Comunidade de Laranjeiras. Depois que suas terras foram demarcadas, margeadas e sem perspectivas de crescimento espacial, viu-se toda uma produção intergeracional desaparecer, dando lugar a uma nova cultura - o fumo, redefinindo valores culturais segundo os interesses da empresa.

A maior parte dos agricultores tem 2-3 ha de terra, enquanto outra parcela expressiva tem área ainda mais reduzida, como consequência da expansão do plantio da empresa. Um dos moradores afirmou: (M.b) "Já estamos ali exprimidos".

Uma parte dos jovens da comunidade permanece trabalhando na empresa fumageira, enquanto outro contingente saiu em busca de trabalho, principalmente em São Paulo e Goiás. Alega-se que tal atitude relaciona-se à falta de vontade dos jovens em vender sua mão de obra à empresa, sobretudo por julgarem que o salário pago por ela é insuficiente para obter os bens materiais desejados (meio de transporte e casa). Então, migrar torna-se uma estratégia para buscar melhores condições salariais, com esperança de retornar e constituir família próxima de seus familiares e entes queridos, eventualmente trabalhando mediante oportunidades que possam surgir na comunidade.

Em um panorama de êxodo rural, os jovens são criados e sustentados por suas famílias no campo, mas depois buscam a cidade sem retribuição produtiva alguma que permita o desenvolvimento rural, que passa a perder sua força de trabalho. A juventude se desloca aos centros urbanos, pois acredita que ali estão as oportunidades de trabalho. Sobre essa constante mobilidade do indivíduo em função do trabalho, Duarte e Luzio (2008) relataram que o trabalhador deve se preparar para deslocar e enfrentar a desterritorialização e o desenraizamento, não se permitindo criar vínculo com nada nem ninguém.

A narrativa aqui apresentada é muito semelhante àquela descrita por Pignatti (2015) em uma comunidade campesina nas imediações da Reserva Particular do Patrimônio Natural (RPPN) do SESC Pantanal, em Mato Grosso. A autora chama atenção para o fato de que as diferentes políticas (ambientais, desenvolvimento econômico, saúde e outras) invariavelmente se sobrepõem num mesmo território, e quase sempre a ciência e o direito são chamados a arbitrar contendas e conflitos.

É neste contexto que Haesbaert (2011) salienta que um dos fenômenos mais frequentes ligados à desterritorialização se relaciona à crescente mobilidade das pessoas, seja como "novos nômades", seja como "vagabundos", viajantes, turistas, imigrantes ou outras necessidades que viesse a impulsionar o deslocamento das pessoas.

É válido destacar que, antes da chegada da empresa, os moradores já cultivavam o fumo, mas em menor escala. Muitos deixaram de plantar com a chegada do empreendimento, e aqueles que ainda cultivam passaram a receber assistência técnica da empresa, que também 
compra a produção, caracterizando o chamado sistema integrado. O problema é que a condição de negociação com os pequenos produtores é desigual e o agricultor se vê obrigado a vender exclusivamente para a empresa compradora.

A empresa, na vida da comunidade, segundo um dos agricultores, constitui-se num mal necessário, pois, apesar de reduzir o espaço da comunidade com seus plantios nos quintais das casas, oferece também empregos à maioria deles. Esse comentário traz à reflexão o que Gianetti (2016) denomina de "tríplice ilusão", uma vez que o homem em Sociedade supervalorizou três aspectos do processo civilizatório (considerado em crise na atualidade, pelo autor). O primeiro, o papel da ciência e sua influência para desvendar todos os mistérios da natureza, dando sentido à vida e à condição humana; o segundo, o fato de a tecnologia submeter essa natureza aos interesses humanos, sem provocar reações contrárias, na direção de um "terrível descontrole das bases naturais da vida"; e terceiro, a ilusão de que o processo civilizatório promoveria a todos nós, a Humanidade, ética e intelectualmente. Assim sendo, e podendo concordar com o autor, é possível que estejamos diante de um "processo civilizatório" em decadência, em que os homens não parecem estar preparados para enfrentar a livre inciativa de produção, aproveitamento da potencialidade das terras e das condições de um modelo globalizado de economia. Nesse caso, de quem é a responsabilidade do concomitante processo de desterritorialização? Certamente, um lado ou outro deve repensar seu papel na Sociedade.

A indústria fumageira, porém, entrou na vida da comunidade de forma ainda mais severa, pois o cultivo, da semente à colheita das folhas, requer forte uso de agrotóxico (SCHOENHALS; FOLLADOR; SILVA, 2009).

A literatura é enfática quanto aos problemas decorrentes do uso de agrotóxicos no cultivo de fumo. Almeida et al. (2012) realizaram estudo quanto ao uso de agrotóxicos por fumicultores em Ivaí, PR, e registraram sintomas de intoxicação crônica decorrentes da constante exposição aos agrotóxicos associados à negligência ou uso inadequado de EPIs, destacando-se: ansiedade e angústia, dores no corpo, nervosismo e até vontade de morrer. Meneghela et al. (2004) destacaram elevados índices de mortalidade por suicídio entre a população de cidades destacadas na produção de fumo. Alguns moradores de Laranjeiras abertamente relataram vivenciar doenças, enquanto outros afirmam desconhecer casos na comunidade (Quadro 1).

Quadro 1 - Trechos retirados de conversa informal com moradores da Comunidade Rural de Laranjeiras, relacionada aos diversos casos de doenças ocasionadas pelo contato direto e/ou indireto com produtos químicos utilizados no monocultivo de fumo

\begin{tabular}{c|l}
\hline Entrevistado(a) & \multicolumn{1}{c}{ Discurso } \\
\hline M.c & $\begin{array}{l}\text { - Meu pai morreu com problemas cardíacos, que aumentou com o trabalho na } \\
\text { indústria fumageira. A indústria fumageira prejudica toda a comunidade; }\end{array}$ \\
\hline M.d & $\begin{array}{l}\text { - Eu estou sentindo direto uma dor de cabeça. Meu filho, quando trabalhava, } \\
\text { sentia muita dor de cabeça; }\end{array}$ \\
\hline M.e & $\begin{array}{l}\text { - Às vezes o pessoal da indústria fumageira se sente mal, porque o produto é } \\
\text { muito forte; }\end{array}$ \\
\hline M.f & - Sim, porque uma prima minha sentiu alguns efeitos, como desmaio; \\
\hline M.g & - Tenho sintoma de alergia e isso pode ser por causa dos produtos; \\
\hline
\end{tabular}




\begin{tabular}{c|l}
\hline Entrevistado(a) & \multicolumn{1}{c}{ Discurso } \\
\hline M.h & $\begin{array}{l}\text { - As pessoas na indústria fumageira toma leite às 21 horas da noite. As } \\
\text { pessoas que saem da indústria fumageira e passam pelo médico, os exames } \\
\text { dão tudo certo, mas com o passar do tempo, fazem exame de sangue e dá água } \\
\text { no sangue e até veneno; }\end{array}$ \\
\hline M.i & $\begin{array}{l}\text {-Em certas ocasiões, quando está ventando e eles utilizam muito veneno no } \\
\text { fumo, as crianças ficam com dificuldades respiratórias; }\end{array}$ \\
\hline M.j & $\begin{array}{l}-E \text { É muita gente doente. Quando aplica aqui, fica um cheio ruim, mas já } \\
\text { acostumei. }\end{array}$ \\
\hline
\end{tabular}

Fonte: Dados da pesquisa (2013).

Constatou-se certo desconforto dos moradores ao comentarem aspectos prejudiciais à saúde causados pela indústria fumageira. Muitos omitiram informações, por medo de falar o que sentem, devido à dependência financeira que a empresa exerce sobre a comunidade. É plausível tal conclusão, pois as pessoas que trabalham na empresa disseram não sentir nada, enquanto aquelas que não trabalham atestam os problemas.

Andrade, Poy e Teixeira (2013), pesquisando sobre o uso de agrotóxicos na Comunidade Rural de Laranjeiras e os efeitos nocivos sobre a saúde humana, verificaram que $72,41 \%$ concordaram ou reconheceram que esses agrotóxicos podem trazer complicações à saúde, enquanto $20,69 \%$ negaram os malefícios do produto à saúde e outros 3,44\% não opinaram.

Quando indagados sobre o problema mais grave existente na comunidade, muitos apontaram a empresa fumageira, por conta dos produtos químicos utilizados nas plantações.

Um morador tentou vender seu terreno por sentir-se ilhado pela empresa, mas não obteve êxito, dada a própria presença da empresa nos arredores da localidade. Afirmou, ainda, que não deseja vender seu bem à empresa, pois ela the oferecera preço abaixo do valor de mercado. Além do mais, a empresa também proíbe que jogue lixo na água de suas represas (o que, num contexto normal, traduz-se numa atitude correta, por evitar a poluição dos corpos d'água da localidade). Contudo, a única preocupação da empresa vai em função de que as águas são utilizadas para irrigar as plantações de fumo e, por isso, devem estar limpas: "Eles tratam o fumo melhor que a gente" (M.I).

É muito provável que os produtos utilizados pela empresa estejam prejudicando a saúde dos moradores de Laranjeiras. Em determinado momento, "M.I" salientou que, quando a empresa pulveriza químicos nas plantações mais próximas às residências e os moradores ameaçam denunciá-la à Justiça, ocorre uma redução da intensidade de aplicação dos produtos.

Embora muitos tenham consciência de que o uso indiscriminado de agrotóxicos nos plantios de fumo em volta da comunidade prejudique a saúde de todos, há uma crença de que aqueles residentes no centro da comunidade não são afetados pelos químicos.

As pessoas que moram no centro da comunidade não são afetadas pela empresa, e sim as que moram perto das plantações de fumo. (M.m).

A época que entro para trabalhar na empresa é a da colheita, o produto já saiu, se eu morasse mais perto poderia causar mal. (M.n).

Apesar de alguns moradores reclamarem em razão do contato com os produtos químicos, seja por via nasal, seja por contato direto, continuam a trabalhar na empresa, considerada um mal necessário, pois não existe alternativa à comunidade, já que as terras remanescentes não 
mais se constituem uma opção, pois não garantem o mesmo poder aquisitivo ofertado pela empresa. Tal interpretação dos fatos se torna visível neste trecho de fala de M.o: "A comunidade está totalmente ilhada pela empresa, já não tendo nem mais o que fazer senão se submeter aos trabalhos na empresa".

O "mal necessário" é passível de questionamentos e deve ser ponderado, embora o Brasil tenha se consolidado, no início desse século, como o segundo maior produtor mundial e o maior exportador de fumo do planeta, graças ao baixo custo de produção, ao sistema de produção integrada e à tendência mundial de deslocamento do cultivo para países em desenvolvimento (VARGAS; CAMPOS, 2005).

Por outro lado, Vargas e Oliveira (2012) pesquisaram 299 produtores rurais em uma região fumageira do Vale do Rio Pardo, no Rio Grande do Sul, e os resultados demonstram que a renda líquida de culturas alternativas ao fumo, como de hortifrutigranjeiros, pode ser superior à obtida por fumicultores. Tais evidências contradizem análises comparativas envolvendo fumo e demais culturas agrícolas geralmente veiculadas pela indústria fumageira. No entanto, cada caso tem suas especificidades, ou seja, as condições de remuneração de cada atividade agrícola dependem do contexto de mercado ao qual estão inseridas e as suas facilidades de escoamentos de produção. Obviamente que os hortifrutigranjeiros podem não ser a alternativa ideal para a Comunidade de Laranjeiras, mas é possível pensar alternativas de diversificação da cultura do fumo, desde que inserida em amplo programa de desenvolvimento territorial. Por fim, retornamos à questão conceitual sobre processo de desterritorialização no contexto sociocultural. Entendemos que tal processo relaciona-se ao desenraizamento (menos ou mais traumático culturalmente) de indivíduos e/ou grupos, e pode implicar a privação do acesso a recursos e riquezas, como parte de um jogo de relações de poder com projeções sobre determinada situação e/ou grupo e lugar.

\section{CONSIDERAÇÕES FINAIS}

A (des)territorialidade e suas repercussões em termos de intervenção na realidade concreta constituem parte do processo de desconstrução daquilo que estava anteriormente posto e consolidado pelas tradições familiares. São as implicações socioculturais e econômicas desse processo que induzem a reintrodução de uma nova dinâmica comunitária.

Os estudos territoriais permitem analisar as relações de poder existentes entre indivíduos, grupos e instituições, que então "territorializam" os espaços conforme seus objetivos e interesses. É possível, de maneira clara e objetiva, identificar interesses econômicos e demais fatores que caracterizam a dinâmica local, sendo possível visualizar os processos de desterritorialidade e desenraizamento das famílias tradicionais. De qualquer forma, o presente estudo permitiu identificar os sujeitos que poderiam ser envolvidos em um processo participativo, condição básica à construção de políticas públicas voltadas ao ordenamento espacial, regulando ou induzindo infraestruturas.

É inegável que a Comunidade Rural de Laranjeiras vivencia evidente perda da identidade, consequência das incessantes investidas da empresa fumageira, que promove a desconstrução da identidade comunitária e a desarticulação e/ou aniquilação da dinâmica social e cultural local. Nota-se que os moradores continuam resistindo com algumas de suas tradições. Destacam-se as manifestações ou festejos religiosos (terno de reis e os novenários em comemoração ao padroeiro da comunidade); práticas laborais do arrendamento de terras para cultivos, em troca de parte da produção junto ao proprietário do terreno; e a troca de diárias no preparo da terra para cultivo 
e/ou manejo vegetal (especialmente o amendoim, a mandioca e a laranja), caracterizado pela troca de favores e o não pagamento monetário da execução da atividade.

Por fim, ressalta-se que a desterritorialização sociocultural e econômica também é acompanhada da expropriação de direitos e costumes tradicionais, além da precarização e/ou exclusão, inseridas na globalização do meio rural por uma ação planejada do capital externo. No entanto, o homem do campo, mesmo o que habita as proximidades urbanas, junto de suas famílias e organizações, deve refletir sobre sua própria responsabilidade neste processo. São os homens que compõem os diversos grupos da Sociedade que criam tais processos e constroem as nações, especificamente a nação brasileira. As entidades, as empresas e os governos são objetos da nossa "revolução cognitiva", que criam nosso imaginário mundo de referências, como forma de sobrevivência e organização evolutiva. Cabe, portanto, a nós, homens do campo, encontrar a forma de enfrentar as dificuldades aqui apontadas.

\section{REFERÊNCIAS}

ABRAMOVAY, R. Para uma teoria dos estudos territoriais. In: MANZANAL, M.; NEIMAN, G.; LATTUADA, M. (Ed.). Desarrollo rural: organizaciones, instituciones y territorios. 1. ed. Ediciones Ciccus: Buenos Aires, 2006.

ALBAGLI, S. Território e territorialidade. In: LAGES, V.; BRAGA, C.; MORELLI, G. (Orgs.). Territórios em movimento: cultura e identidade como estratégia de inserção competitiva. 1. ed. Rio de Janeiro: Relume Damará/Brasília: SEBRAE, 2004.

ALMEIDA, E. A.; ZIMMERMANN, M. H.; GONÇALVES, C. S.; GRDEN, C. R. B.; MACIEL, M. A. S.; BAIL, L.; ITO, C. A. S. Agrotóxicos e o risco à saúde entre fumicultores. Publicatio UEPG: Ciências Biológicas e da Saúde, Ponta Grossa, v. 17, n. 2, p. 133-9, jul./dez. 2012.

ANDRADE, M. A.; POY, C. D.; TEIXEIRA, M. C. Formas de utilização e percepção de risco do uso de agrotóxicos por agricultores na comunidade laranjeiras, município de Muritiba-BA. In: SEABRA, G. (Org.). Congresso Nacional de Educação Ambiental e do Encontro Nordestino de Biogeografia: educação e cooperação pela água para a conservação da biodiversidade. 3. ed. João Pessoa: Editora da UFPB, 2013.

BORTONE, F. A. S.; LUDWIG, M. P.; XAVIER, K. D. Contradições da modernidade no processo de des/re/ territorialização do lugar: o caso dos atingidos pela construção da Hidrelétrica Candonga. Revista ELO Diálogos em Extensão, Viçosa, v. 5, n. 2, p. 1-12, out. 2016.

BOSI, E. Cultura e desenraizamento. In: BOSI, A. (Org.). Cultura brasileira: temas e situações. 4. ed. São Paulo: Ática, 1999.

BRASIL. Ministério do Desenvolvimento Agrário. Referências para a gestão social de territórios rurais. Brasília-DF: MDA, 2005. Disponível em: http://sge.mda.gov.br/bibli/documentos/tree/doc_216-28-112012-11-38-397290.pdf. Acesso em: 10 fev. 2018.

DANNA, M. F.; MATOS, M. A. Apreendendo a observar. 2. ed. São Paulo: Edicon, 2006.

DUARTE, D. A.; LUZIO, C. A. (Des) territorialidade: caminhos percorridos por trabalhadores sujeitos ao processo migratório interno e sua relação subjetiva com o trabalho. In: BATISTA, R. L. (Org). Anais do VI Seminário do Trabalho: trabalho, economia e educação. 1. ed. Marília: Ed. Grafica Massoni, 2008.

FREITAS, A. F. Por uma abordagem relacional do desenvolvimento territorial rural. Revista de Economia e Sociologia Rural, Piracicaba, v. 54, n. 4, p. 667-90, out./dez. 2016. 
GIANNETTI, E. Trópicos utópicos. 1. ed. São Paulo: Cia. das Letras, 2016.

HAESBAERT, R. O Mito da Desterritorialização: do "fim dos territórios" à multiterritorialidade. 6. ed. Rio de Janeiro: Bertrand Brasil, 2011.

HAESBAERT, R. Território e multiterritorialidade: um debate. GEOgraphia, Niterói, v. 9, n. 17, p. 19-46, 2007.

HAESBAERT, R. O mito da desterritorialização: do "fim dos territórios" à multiterritorialidade. 2. ed. Rio de Janeiro: Bertrand Brasil, 2004a.

HAESBAERT, R. Des-caminhos e perspectivas do território. In: RIBAS, A. D.; SPOSITO, E. S.; SAQUET, M. A. (Org.). Território e desenvolvimento: diferentes abordagens. Francisco Beltrão: Unioeste, 2004b.

IANNI, O. A sociedade global. 2. ed. Rio de Janeiro: Civilização Brasileira, 1993.

INSTITUTO BRASILEIRO DE GEOGRAFIA E ESTATÍSTICA. Estimativas da população residente no Brasil e unidades da federação com data de referência em 1o de julho de 2017. Rio de Janeiro: IBGE, 2017. Disponível em: https://www.ibge.gov.br/informacoes-por-cidade-e-estado.html?t=destaques\&c=2922300. Acesso em: 5 dez. 2018.

KAPLAN, C. Deterritorializations: the rewriting of home and exile in Western Feminist discourse. In: JANMOHAMMED, A.; LLOYD, D (Ed.). The nature and context of minority discours. Nova York; Oxford: Oxford University Press, 1990.

MeneghelA, S. N.; VICTORAB, C. G.; FARIAC, N. M. X.; CARVALHOD, L. A.; FALKE, J. W. Características epidemiológicas do suicídio no Rio Grande do Sul. Revista de Saúde Pública, São Paulo, v. 38, n. 6, p. 804-10, maio 2004.

MORAES, A. C. R.; COSTA, W. M. Geografia crítica: a valorização do espaço. 2. ed. São Paulo: Hucitec, 1984.

OLIVEIRA, A. M. C. V. S. Processos de desterritorialização e filiação ao lugar: o caso da Aldeia da Luz. 2011. 171p. Dissertação (Mestrado em Geografia Humana, Planeamento e Territórios Saudáveis) - Universidade de Coimbra, Coimbra, PT, 2011.

PAGÈS, M., BONETTI, M.; GAULEJAC, V. O poder das organizações. 1. ed. São Paulo: Atlas, 1987.

PIGNATTI, M. G. No caminho da proteção ambiental: ações para a saúde humana e ambiente na população campesina do Pantanal Mato-Grossense, Brasil. Cadernos Saúde Coletiva, Rio de Janeiro, v. 23, n. 4, p. 453-9, out. 2015.

PIMBERT, M. P.; PRETTY, J. N. Parques, comunidades e profissionais: incluindo "participação" no manejo de áreas protegidas. In: DIEGUES, A. C. (Org.). Etnoconservação: novos rumos para a proteção da natureza nos trópicos. 2. ed. São Paulo: UCITEC, 2000.

RAHNEMA, M. Participation. In: SACHS, W. (Ed). The Development Dictionary. 2. ed. Londres: Zed Books Ltda., 1992.

SACK, R. D. Human territoriality: its theory and history. Cambridge: Cambridge University Press, 1986.

SANTOS, A. V.; SILVA, M. A. S. Avaliação de características habitacionais de domicílios rurais em recortes territoriais sergipanos. Revista de Economia e Sociologia Rural, Piracicaba, v. 54, n. 1, p. 109-30, jan./ mar. 2016. 
SANTOS, D. M.; TEIXEIRA, M. C.; MENDEZ, J. M. D.; PUGAS, A. S. Tipologias biofílicas na percepção sobre a caça em uma comunidade rural do recôncavo da Bahia: subsídios à Educação Ambiental para conservação da biodiversidade. Revista Brasileira de Educação Ambiental, São Paulo, v. 10, n. 2, p. 25-35, jun. 2015.

SANTOS, M. A natureza do espaço: espaço e tempo - razão e emoção. 3. ed. São Paulo: Hucitec, 1999.

SCHNEIDER, S.; TARTARUGA, I. G. P. Território e abordagem territorial: das referências cognitivas aos aportes aplicados à análise dos processos sociais rurais. Revista Raízes, Campina Grande, v. 23, n. 1 e 2, p. 99-116, jan./dez. 2004.

SCHOENHALS, M.; FOLLADOR, C. A. F.; SILVA, C. Análise dos impactos da fumicultura sobre o meio ambiente, à saúde dos fumicultores e iniciativa de gestão ambiental na indústria do tabaco. Engenharia Ambiental: Pesquisa e Tecnologia, Espírito Santo do Pinhal, v. 6, n. 2, p. 16-37, maio/ago. 2009.

SILVA, S. P. A abordagem territorial no planejamento de políticas públicas e os desafios para uma nova relação entre estado e sociedade no Brasil. Cadernos Gestão Pública e Cidadania, São Paulo, v. 17, n. 60, p. 148-168, jan./jun. 2012.

SOJA, E. W. The political organization of space. 1. ed. Washington: Association of American Geographers, 1971.

TEIXEIRA, O. A.; MELO, R. L.; FRANÇA, V. L. A. A experiência de territorialização para o planejamento regional em Sergipe. Economia Política do Desenvolvimento, Maceió, v. 14, n. 12, p. 91-128, set./dez. 2011.

TUAN, Y. F. Espaço e Lugar: a perspectiva da experiência. São Paulo: DIFEL, 1983.

TUAN, Y. F. Topofilia: um estudo da percepção, atitudes e valores do meio ambiente. Ed. São Paulo: DIFEL, 1980.

VARGAS, M. A.; OLIVEIRA, B. F. Estratégias de diversificação em áreas de cultivo de tabaco no Vale do Rio Pardo: uma análise comparativa. Revista de Economia e Sociologia Rural, Piracicaba, v. 50, n. 1, p. 157-74, jan./mar. 2012.

VARGAS, M. A.; CAMPOS, R. R. Crop substitution and diversification strategies: empirical evidence from selected brazilian municipalities. Washington, DC: The World Bank, 2005. Disponível em: http://citeseerx. ist.psu.edu/viewdoc/download?doi=10.1.1.529.6787\&rep=rep1\&type=pdf. Acesso em: 5 fev. 2018.

VIANNA, H. M. Pesquisa em educação: a observação. 5. ed. Brasília: Líber Livro Editora, 2007.

WEIL, S. A. O enraizamento. 1. ed. Bauru: EDUSC, 2001.

\section{Sobre os autores:}

Divaney Mamédio: Doutor em Zootecnia pela Universidade Estadual de Maringá (UEM), Paraná, Brasil. E-mail: divaney.zootecnia@gmail.com, Orcid: http://orcid.org/0000-0003-3514-5982

Jesus Manuel Delgado Mendez: Doutor em Recursos Florestais pela Universidade de São Paulo (USP). Docente do Centro de Ciências Agrárias, Ambientais e Biológicas da Universidade Federal do Recôncavo da Bahia (UFRB). Tutor do Programa de Educação Tutorial Conexões de Saberes Socioambientais. E-mail: jesus@ufrb.edu.br, Orcid: http://orcid.org/0000-0001-5730-7925

Renato de Almeida: Doutor em Oceanografia pela Universidade de São Paulo (USP). Docente do Centro de Ciências Agrárias, Ambientais e Biológicas, Universidade Federal do Recôncavo da Bahia (UFRB). E-mail: renato.almeida@ufrb.edu.br, Orcid: http://orcid.org/0000-0002-1242-3495 
Simone Barequeiro de Santana: Graduanda em Tecnologia de Gestão em Cooperativas, Centro de Ciências Agrárias, Ambientais e Biológicas na Universidade Federal do Recôncavo da Bahia (UFRB). E-mail: simone.ta@hotmail.com, Orcid: http://orcid.org/0000-0003-3403-2206 